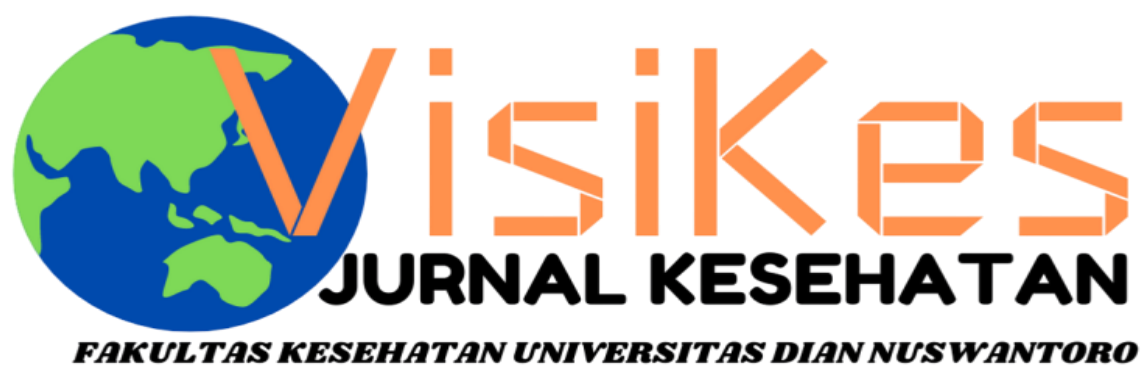

ISSN 1412-3746

FAKULTAS KESEHATAN UNIVERSITAS DIAN NUSWANTORO

Persepsi Mahasiswa Keperawatan Tentang Eskalasi Tenaga Perawat

Rendi Ariyanto Sinanto', Vivi Retno Intening ${ }^{2}$

Risiko kesehatan $\mathrm{Pb}$ dan $\mathrm{Hg}$ pada sayuran di desa Kopeng Kabupaten Semarang

Indira Casheila Anindityo ${ }^{1}$, Nur Endah Wahyuningsih ${ }^{2}$, Yusniar Hanani Darundiati ${ }^{3}$

Analisis Pelaksanaan Program Indonesia Sehat Dengan Pendekatan Keluarga (Pispk) Dalam Capaian Indeks Keluarga

Sehat Di Kabupaten Brebes Tahun 2020 Studi Pada Puskesmas Kluwut Kabupaten Brebes

Rizky Aprilianti Lestari ${ }^{1}$ dr. Antono Suryoputro ${ }^{1}$ Dr. dr. Apoina Kartini. M. Kes ${ }^{1}$

Disiplin Keselamatan dan Kesehatan Kerja melalui pemakaian alat pelindung diri di laboratorium kimia PT Sucofindo

Jakarta

Susan Endah Kartikasari ${ }^{1}$, Tatan Sukwika ${ }^{2}$

Perbedaan Pengetahuan Anemia dan Tablet Tambah Darah (TTD) Sebelum dan Sesudah Pendidikan Kesehatan Melalui

Media Video dan Aplikasi Quizlet

Devita Sari ${ }^{1}$, Gisely Vionalita ${ }^{2}$

Tingkat Pengetahuan Dan Perilaku Mahasiswi Mengenai Legalitas Dan Keamanan Kosmetik

Hani Sri Fitriani, Rizki Siti Nurfitria

Evaluasi Manajemen Dokumen Rekam Medis Di Filing Aktif Rumah Sakit Swasta Kabupaten Semarang

Bobby Anggara Laksana Putra ${ }^{1}$, Retno Astuti Setjaningsih ${ }^{2}$

Tingkat Pengetahuan Gizi Seimbang dan Profil Kesehatan Sopir Bus Antar Kota

Vilda Ana Veria Setyawati ${ }^{1}$, Bayu Yoni Setyo Nugroho ${ }^{1}$

Pengaruh Pengetahuan Dan Motivasi Kerja Terhadap Penerapan Early Warning Score System Di Rsup H Adam Malik Ita Riahna Pinem ${ }^{1}$, Zulfendri', Siti Saidah Nasution ${ }^{3}$

Analisis Penelusuran Masker Sebagai Protokol Kesehatan Saat Pandemi Covid-19 Di Indonesia: Studi Google Trends Ully Febra Kusuma ${ }^{1}$, Nurunnisa Arsyad ${ }^{2}$, Melissa Shalimar Lavinia ${ }^{3}$, Selvia Rahayu ${ }^{4}$, M. Khairul Kahfi , Rizma Adllia Syakurah ${ }^{6}$ Perilaku Hidup Bersih Dan Sehat (Phbs) Dengan Kejadian Sakit Pada Siswa Sekolah Dasar Di Kabupaten Banyumas Windri Lesmana Rubai ${ }^{1}$, Pramesthi Widya Hapsari', Katri Andirini Surijati ${ }^{3}$

Identifikasi Risiko Ganguan Muskuloskletal Pada Pekerja Percetakan Dengan Metode Nordic Body Map

Octavianus Hutapea ${ }^{1}$, Moch.Sahri', Rustam Basuki ${ }^{3}$

Literatur review: Implementasi Bauran Pemasaran 7P Terhadap Tingkat Kepuasan Pasien Di Rumah Sakit

Desi Natalia Marpaung ${ }^{1}$ Ernawaty $^{2}$ Diansanto Prayoga ${ }^{3}$ Syifa'ul Lailiyah $^{4}$

Kelengkapan Informasi Medis Untuk Mendukung Kodefikasi Penyakit Jantung Guna Mewujudkan Kualitas Data Informasi Medis Di Rumah Sakit Islam Sultan Agung Semarang

Dyah Ernawati ${ }^{1}$, Ratna Rifatul Ulya ${ }^{2}$, Arif Kurniadi ${ }^{3}$

Kajian Faktor Kendala Dokter Tidak Menggunakan Aplikasi Wifi Tb Di Kota Semarang

Arif Kurniadi', Evina Widianawati2, Dyah Ernawati ${ }^{3}$

Analisis Pelaksanaan Program Penanggulangan Tuberkulosis Paru Di Puskesmas Purwoyoso Kota Semarang

Nahari Ratu Cempaka Wilis ${ }^{1}$ Hardi Warsono ${ }^{2}$ M. Sakundarno Adi ${ }^{3}$

Hubungan Penggunaan Alat Pelindung Diri (Apd) Dengan Kadar Sgot Dan Sgpt Dalam Darah Pada Petani Padi

Iga Maliga, Rafi'ah

Faktor Risiko Kejadian Stunting Pada Balita di Wilayah Kerja Puskesmas Pandan Kabupaten Sintang

${ }^{1}$ Agustini Elisabet, ${ }^{2}$ Elvi Juliansyah

Peran Suami Dan Petugas Kesehatan Dengan Deteksi Dini Kanker Serviks

Christina Leasa, ${ }^{1}$ Mariene Wiwin Dolang

Analisis Penerapan Protokol Kesehatan terhadap Tingkat Kepatuhan Pada Pekerja informal Selama Pandemi Covid-19

MG Catur Yuantari ${ }^{1}$, Enny Rachmani ${ }^{2}$, Eti Rimawati ${ }^{1}$, Sri Handayani ${ }^{1}$, Edi Jaya Kusuma ${ }^{2}$

Peran Pengawas Minum Obat Dan Pendampingan Berobat Ulang Dengan Keberhasilan Pengobatan Tb Paru

Taswin $^{\left.1^{*}\right)}$, (zan $^{1)}$, Wahyuddin $^{1)}$, Dahmar ${ }^{1)}$

Faktor Determinan Sosial Dan Gambaran Kejadian Post Traumatic Syndrome Disorder (Ptsd) Pasca Banjir Di Dki Jakarta

Dan Bekasi Tahun 2020

Thresya Febrianti ${ }^{1}$, Nurfadhillah ${ }^{2}$, Mitha Nurhjanah ${ }^{3}$, Tiara Kautsa Aliefya ${ }^{4}$

Perbedaan Pola Makan Pada Balita Stunting Dan Tidak Stunting Di Kecamatan Teon Nila Serua (Tns) Kabupaten Maluku Tengah

Trixie Leunupun ${ }^{1}$, Ani Margawati' ${ }^{2}$ Annastasia Ediati ${ }^{3}$

Gambaran Pengelolaan Rekam Medis Rawat Inap Di Rsud Syekh Yusuf Kab. Gowa Tahun 2019

Zilfadhilah Arranury*, Surahmawati, Muhammad Rusmin, Tri Addya Karini, Dian Rezki Wijaya, Ranti Ekasari, Jihan Sulfitri

Analisis Risiko Kesehatan dalam Pemanfaatan Kemball Limbah Sludge Industri Makanan PT. X

Sri Slamet Mulyati ${ }^{1}$, Fajar Sihite ${ }^{2}$ 


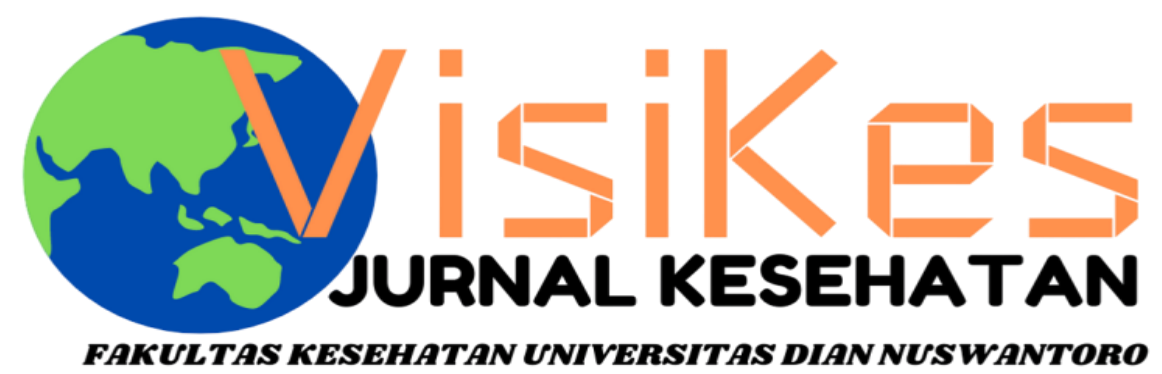

Volume 20, Nomor 1, April 2021

\section{Ketua Redaksi}

Dr. Drs. Slamet Isworo, M.Kes

\section{Penyunting}

Enny Rachmani, SKM, M.Kom, Ph.D

Fitria Wulandari, SKM, M.Kes

\section{Sekretariat}

Lice Sabata, SKM

Desain dan Layout

Puput Nur Fajri, SKM

\section{Alamat Redaksi}

Fakultas Kesehatan Universitas Dian Nuswantoro Jl. Nakula I No. 5-11 Semarang Telp/fax. (024) 3549948

email : visikes@fkes.dinus.ac.id

website $\quad$ : http://publikasi.dinus.ac.id/index.php/visikes/index

VisiKes diterbitkan mulai Maret 2002

Oleh Fakultas Kesehatan Universitas Dian Nuswantoro 


\title{
Kajian Faktor Kendala Dokter Tidak Menggunakan Aplikasi Wifi Tb Di Kota Semarang
}

\author{
Arif Kurniadi ${ }^{1}$, Evina Widianawati ${ }^{2}$, Dyah Ernawati ${ }^{3}$ \\ Corresponding author: Evina Widianawati
1,2,3 Program Studi D3 Rekam Medis dan Informasi Kesehatan Fakultas Kesehatan Universitas Dian Nuswantoro Semarang

Email: arif.kurniadi@dsn.dinus.ac.id, evina.widianawati@dsn.dinus.ac.id, dyah.ernawati@dsn.dinus.ac.id

\begin{abstract}
ABSTRAK
Tuberkulosis (TB) merupakan salah satu dari sepuluh penyakit penyebab kematian di dunia dengan angka kejadian 10,0 juta (kisaran, 9,0-11,1 juta) penderita TB pada tahun 2018. Dalam pengelolaannya, kasus TB yang ditemukan harus dicatat dan dilaporkan oleh setiap fasilitas pelayanan kesehatan sesuai format yang ditentukan. Upaya pemberdayaan secara aktif untuk pelaporan kasus dilakukan dokter dengan bantuan teknologi menggunakan aplikasi WifiTB. Penelitian ini bertujuan untuk mengkaji faktor-faktor kendala yang menyebabkan dokter tidak menggunakan aplikasi WifiTB di wilayah kerja Dinas Kesehatan Kota Semarang. Data diperoleh lewat kuesioner dengan skala linkert yang diisi oleh dokter sebagai pemakai aplikasi sebanyak 129 kuesioner dengan mengolah 77 kuesionar dokter yang belum menggunakan aplikasi. Dengan menggunakan teknik analisis faktor, hasil penelitian menunjukkan bahwa persepsi negatif $86,2 \%$, tipe smartphone $79,5 \%$ dan kesiapan $78,5 \%$ paling mempengaruhi dokter dalam menggunakan aplikasi WifiTB. Untuk mengurangi persepsi negative dokter dalam menggunakan aplikasi wifi TB maka diperlukan komunikasi intensif kepada dokter agar menambah keyakinan dan kesiapan para dokter dalam menggunaan aplikasi WifiTB.
\end{abstract}

Kata kunci: Tuberkulosis, aplikasi, Wifi TB, persepsi, factor

\begin{abstract}
Tuberculosis (TB) is one of the top ten causes of death in the world with an incidence of 10.0 million (range, 9.0-11.1 million) TB sufferers in 2018. In its management, TB cases found must be recorded and reported. by each health service facility according to the prescribed format. The active empowerment effort for reporting cases is carried out by doctors with the help of technology using the WifiTB application. This study aims to examine the constraining factors that cause doctors not to use the WifiTB application in the working area of the Semarang City Health Office. Data obtained through a questionnaire with a linkert scale filled out by doctors as application users as many as 129 questionnaires by processing 77 questionnaires for doctors who have not used the application. By using factor analysis techniques, the results showed that the negative perception was $86.2 \%$, the type of smartphone was $79.5 \%$ and the readiness of $78.5 \%$ influenced doctors the most in using the WifiTB application. To reduce the negative perception of doctors in using the WiFi TB application, intensive communication with doctors is needed to increase the confidence and readiness of doctors in using the WifiTB application.
\end{abstract}

Keywords: Tuberculosis, application, Wifi TB, perception, factor

\section{PENDAHULUAN}

Menurut WHO (World Health

Organization), Tuberkulosis (TB) merupakan

salah satu dari 10 penyakit penyebab kematian ${ }^{[1]}$. Penderita TB dengan pemeriksaan BTA (Basil Tahan Asam) positif adalah sumber penularan kasus TB, melalui udara yang telah tercemar oleh bakteri Mycobacterium Tuberculosis saat penderita TB paru batuk mengeluarkan dahak serta 
melalui percikan air liur yang tercemar di udara [2]. Tidak hanya pasien dengan BTA positif, tingkat penularan sebesar $65 \%$ juga dapat ditularkan oleh pasien dengan pemeriksaan BTA negatif, $26 \%$ adalah penularan oleh pasien dengan hasil pemeriksaan kultur negatif, sedangkan 17\% penularan oleh pasien hasil pemeriksaan kultur negatif dan foto thorax positif. Dalam batuk atau bersin yang dikeluarkan oleh pasien TB mengandung sekitar 3000 percikan dahak ${ }^{[3]}$.Pasien TB yang sering memiliki penyakit penyerta dan kerusakan pada paruparu, membuat penderita sangat rentan terhadap COVID-19 pada masa pandemi seperti saat ini. Gejala TB dan COVID-19 bisa serupa yaitu batuk dan demam, dimana hal ini bisa menyebabkan kebingungan dalam diagnosis dan bahkan dapat memperburuk stigmatisasi pasien TB ${ }^{[4]}$.

Profil Kesehatan di Indonesia tahun 2017 memperkirakan terdapat 992.441 kasus TB. Jumlah perkiraan kasus TB terbanyak di 5 wilayah di Indonesia yaitu di Jawa Barat dengan 156.149 kasus, Jawa Timur terdapat 119.490, Jawa Tengah terdapat 103.840 kasus, Sumatera Utara terdapat 73.488 kasus, dan Sumatera Selatan terdapat 40.311 kasus [5].Kementerian Kesehatan Republik Indonesia telah mengupayakan berbagai cara untuk menekan angka kasus Tuberculosis (TBC). Target yang akan dicapai pada tahun 2030 adalah insiden TBC menurun 80 persen dan tahun 2050 tidak ada lagi kasus baru TBC. Strategi pengendalian kasus TB dilakukan dengan strategi DOTS (Directly Observed Treatment Short-Course) yang memfokuskan pada penemuan dan penyembuhan pasien TB yang memprioritaskan pada pasien TB menular. Selain itu untuk kemudahan dalam pelaporan penemuan kasus terduga TB/kasus TB dengan memanfaatkan teknologi dalam bentuk aplikasi Wajib Notifikasi TB (Wifi TB) yang menyasar penggunanya berupa Dokter Praktik Mandiri (DPM) maupun dokter di klinik pratama yang terkait dengan surveilans TB. Untuk itu untuk mengukur keberhasilan implementasi aplikasi WIFI TB berbasis android perlu dilakukan dengan melakukan survey kepada pengguna.

Sasaran pengguna aplikasi Wifi TB adalah DPM (Dokter Praktik Mandiri) maupun klinik yang terkait dengan surveilans TB. Di Wilayah kerja Dinas Kesehatan Provinsi Jawa Tengah telah melaksanakan desiminasi aplikasi Wifi TB diawali dengan diselenggarakannya workshop pada tanggal 23-24 Agustus 2018 bekerjasama dengan CTB (Challenge Tuberculosis) KNCV Provinsi Jawa Tengah kepada pengelola program TB Kabupaten/Kota se-Jawa Tengah. Setelah penyelenggaraan workshop tersebut, Dinas Kesehatan Kab/Kota melakukan koordinasi dengan IDI (Ikatan Dokter Indonesia) terhadap penggunaan aplikasi Wifi TB. Penelitian ini dilakukan di wilayah kerja setiap Puskesmas di Kota Semarang yang sudah terpapar oleh sosialisasi penggunaan aplikasi Wifi TB kepada dokter praktik mandiri, klinik pratama yang berada di wilayah kerja Dinas Kesehatan Kota Semarang. Namun demikian pada kenyataanya ada beberapa dokter yang tidak menggunakan aplikai WifiTB ini. [6] 
Penelitian ini bertujuan untuk mengetahui faktor utama kendala dokter tidak menggunakan aplikasi WIFI TB.

\section{METODE}

Jenis penelitian yang digunakan adalah penelitian deskriptif dengan pendekatan kuantitatif yaitu analisis kuantitatif secara deskriptif, dan analisis kuantitatif secara inferensial. Variabel penelitian sebagai berikut: usia, jenis kelamin, jenis instansi, lama bekerja, pelatihan, akses informasi, jenis smartphone, persepsi negatif, pengoperasian dan kesiapan menggunakan aplikasi WIFI TB. Populasi yang digunakan dalam penelitian ini adalah Dokter Praktek Mandiri (DPM) dan Dokter di Klinik Pratama (DKP) di wilayah kerja Dinas Kesehatan Kota Semarang. Jumlah responden yaitu 129 responden. Dan dari 129 responden ini yang belum menggunakan aplikasi wifiTB sebesar 77 responden. Sample menggunakan semua data dari total populasi. Instrument penelitian yang digunakan berupa angket penggunaan aplikasi Wifi TB dan dokumentasi. Dilakukan analisis deskriptif pada data angket yaitu data profil responden, data hasil kuesioner di setiap variable, setiap item pertanyaan di variabel penelitian. Analisis dilakukan dengan menggunakan rumus Mean, Modus dan Presentase. Dilakukan analisis faktor pada data angket yaitu pada pengaruh variabel penelitian.

\section{HASIL DAN PEMBAHASAN}

Dari angket yang diberikan kepada responden diperoleh ringkasan deskriptif seperti pada tabel 1.

Tabel 1. Ringkasan analisis deskriptif

\begin{tabular}{|c|c|c|c|}
\hline Deskripsi & Kriteria / AVG & Jumlah & $\%$ \\
\hline Usia & $\begin{array}{l}>45 \text { th } \\
<=45 \text { th }\end{array}$ & $\begin{array}{l}59 \\
18\end{array}$ & $\begin{array}{l}77 \% \\
23 \%\end{array}$ \\
\hline Gender & $\begin{array}{l}\mathrm{L} \\
\mathrm{P}\end{array}$ & $\begin{array}{l}29 \\
48\end{array}$ & $\begin{array}{l}38 \% \\
62 \%\end{array}$ \\
\hline Jenis Instansi & $\begin{array}{l}\text { DPM } \\
\text { DKP }\end{array}$ & $\begin{array}{l}18 \\
59\end{array}$ & $\begin{array}{l}23 \% \\
77 \%\end{array}$ \\
\hline Lama Bekerja & $\begin{array}{l}>10 \text { th } \\
<=10 \text { th }\end{array}$ & $\begin{array}{l}25 \\
52\end{array}$ & $\begin{array}{l}32 \% \\
68 \% \\
\end{array}$ \\
\hline Pelatihan & $\begin{array}{l}\text { Ya } \\
\text { Tidak }\end{array}$ & $\begin{array}{l}13 \\
64\end{array}$ & $\begin{array}{l}17 \% \\
83 \%\end{array}$ \\
\hline Akses informasi & $\begin{array}{l}3.2 \\
>=3.0 \\
<3.0\end{array}$ & $\begin{array}{l}51 \\
26\end{array}$ & $\begin{array}{l}66 \% \\
34 \%\end{array}$ \\
\hline Persepsi Negatif & $\begin{array}{l}2.9 \\
>=3.0 \\
<3.0\end{array}$ & $\begin{array}{l}45 \\
32\end{array}$ & $\begin{array}{l}58 \% \\
42 \%\end{array}$ \\
\hline Pengoperasian & $\begin{array}{l}3.2 \\
>=3.0 \\
<3.0\end{array}$ & $\begin{array}{l}53 \\
24\end{array}$ & $\begin{array}{l}69 \% \\
31 \%\end{array}$ \\
\hline Smartphone & $\begin{array}{l}2.8 \\
>=3.0 \\
<3.0\end{array}$ & $\begin{array}{l}43 \\
34\end{array}$ & $\begin{array}{l}56 \% \\
44 \%\end{array}$ \\
\hline Kesiapan & $\begin{array}{l}3.0 \\
>=3.0 \\
<3.0\end{array}$ & $\begin{array}{l}55 \\
22\end{array}$ & $\begin{array}{l}71 \% \\
29 \%\end{array}$ \\
\hline
\end{tabular}


Berdasarkan tabel 1 diatas dari 129 responden terdapat 52 responden sudah menggunakan aplikasi, namun 77 responden yang tidak menggunakan aplikasi WifiTB, artinya sebanyak $60 \%$ dokter di Semarang tidak menggunakan aplikasi Wifi TB. Jika dilihat dari segi usia, dan mayoritas usia diatas 45 tahun yang tidak menggunakan aplikasi sebesar 77\%. Dari tabel 1 terlihat bahwa kendala terbesar terdapat pada $83 \%$ dokter (64 responden) tidak mengikuti pelatihan Wifi TB. Akses informasi mendapatkan skor 3,2 dari skala 5 point, persepsi negatif mendapat skor 2,9, pengoperasian aplikasi mendapat skor 3,2, jenis smartphone mendapat skor 2,8 dan kesiapan penggunaan aplikasi mendapat skor 3. Dari beberapa faktor tersebut yang menjadi kendala dengan skor rendah yaitu jenis smartphone dan persepsi negatif. Selanjutnya akan dilakukan uji analisis faktor tahap awal yaitu uji KMO dan anti-image correlation untuk mengetahui faktor-faktor yang dapat dilakukan analisis lebih lanjut untuk menjadi faktor dominan yang disajikan di table 2 .

Tabel 2. Hasil Sig KMO dan Anti-image Correlation

\begin{tabular}{|c|c|c|c|}
\hline Step & Step 1 & Step 2 & Step 3 \\
\hline KMO Siq & .000 & .000 & .000 \\
\hline Age & 0,509 & 0,462 & - \\
\hline 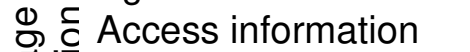 & 0,406 & - & - \\
\hline$\underset{\varepsilon}{\mathbb{E}} \underset{\pi}{\pi}$ Negative Perception & 0,591 & 0,657 & 0,651 \\
\hline 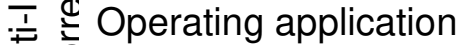 & 0,532 & 0,810 & 0,841 \\
\hline 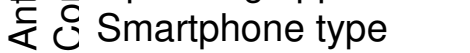 & 0,533 & 0,706 & 0,702 \\
\hline Readiness & 0,740 & 0,705 & 0,744 \\
\hline
\end{tabular}

Dari tabel 2 diperoleh Nilai Sig KMO < 0,05 sehingga penelitian dapat dilanjutkan. Selanjutnya dilakukan analisis matriks korelasi, yang bertujuan untuk mengetahui apakah beberapa faktor yang ada tersebut memiliki korelasi yang erat antar sesamanya atau tidak sama sekali. Dari tabel 2 diketahui bahwa Anti-Image Correlation tahap I terdapat satu faktor mendapatkan nilai di bawah 0,5 sehingga faktor tersebut harus dihilangkan yaitu faktor akses informasi. Selanjutnya dilakukan uji KMO ulang dengan menghilangkan faktor akses informasi agar penelitian dapat dilanjutkan.

Berdasarkan uji ke-2 KMO dari tabel 2 diatas diperoreh nilai Sig $<0,05$ sehingga penelitian dapat dilanjutkan. Dari tabel 2 diketahui bahwa Anti-Image Correlation tahap II terdapat satu faktor mendapatkan nilai di bawah 0,5 sehingga faktor tersebut harus dihilangkan yaitu faktor usia. Selanjutnya dilakukan uji KMO ulang dengan menghilangkan faktor usia agar penelitian dapat dilanjutkan. Berdasar uji ke-3 KMO dari tabel 2 diatas diperoreh nilai Sig $<0,05$ sehingga penelitian dapat dilanjutkan. Selanjutnya dilakukan analisis matriks korelasi yang bertujuan untuk mengetahui apakah beberapa faktor yang ada tersebut memiliki korelasi yang erat antar sesamanya atau tidak sama sekali. Diketahui bahwa AntiImage Correlation tahap III semua faktor yaitu 
persepsi negatif, pengoperasian, jenis smartphone dan kesiapan mendapatkan nilai di atas 0,5 sehingga penelitian dapat dilanjutkan. Langkah selanjutnya adalah ditetapkan jumlah komponen yang akan terbentuk dari berbagai faktor yang ada dengan menggunakan hasil SPSS pada kolom Total Variance Explained yang disajikan pada tabel 3.

Tabel 3. Total Variance Explained

\begin{tabular}{|c|c|c|c|c|c|c|}
\hline \multirow{2}{*}{ Component } & \multicolumn{3}{|c|}{ Initial Eigenvalues } & \multicolumn{3}{|c|}{ Extraction Sums of Squared Loadings } \\
\hline & Total & $\%$ of Variance & Cumulative \% & Total & $\%$ of Variance & Cumulative \% \\
\hline 1 & 2,160 & 54,001 & 54,001 & & & \\
\hline 2 & 0,902 & 22,559 & 76,560 & 2,160 & 54,001 & 54,001 \\
\hline 3 & 0,563 & 14,065 & 90,625 & & & \\
\hline 4 & 0,375 & 9,375 & 100,000 & & & \\
\hline
\end{tabular}

Dari tabel 3 diketahui bahwa terdapat 1 komponen dengan nilai eigen lebih dari satu, yaitu komponen 1 dengan nilai eigen 2,160 sehingga akan terbentuk satu komponen utama yaitu komponen 1 dengan nilai variance 54,001\%. Selanjutkan akan dianalisis korelasi setiap variabel dengan ketiga komponen utama, dan hasilnya tampak pada tabel 4.

Tabel 4. Component Matrix ${ }^{a}$

\begin{tabular}{cc}
\hline \multicolumn{2}{c}{ Component 1} \\
\hline Negative Perception &. $\mathbf{8 6 2}$ \\
Operating application & .417 \\
Smartphone type & .795 \\
Readiness & .785 \\
\hline
\end{tabular}

Dari tabel 4 diatas diketahui bahwa persepsi negatif berkolerasi dengan komponen 1 sebesar $86,2 \%$,pengoperasian aplikasi berkorelasi ke komponen 1 sebesar $41,7 \%$, jenis smartphone berkorelasi ke komponen 1 sebesar 79,5\%, kesiapan berkorelasi ke komponen 1 sebesar 78,5\%. Korelasi tertinggi pada komponen 1 yaitu persepsi negatif $86,2 \%$, tipe smartphone $79,5 \%$ dan kesiapan 78,5\%. Dari informasi tersebut diketahui bahwa faktor dominan yang mempengaruhi kendala tidak menggunakan aplikasi wifi TB adalah persepsi negatif, smartphone dan kesiapan ${ }^{[7]}$.
Menurut Sarlito W. Sarwono, 2010 faktor-faktor yang mempengaruhi persepsi berupa perhatian dan fokus pada sesuatu, kesiapan mental seseorang terhadap rangsangan yang akan timbul, kebutuhan sesaat maupun menetap pada setiap individu, sistem nilai yang berlaku dalam suatu masyarakat, serta tipe kepribadian ${ }^{[8]}$. Dari hasil penelitian diketahui bahwa persepsi negatif, jenis smartphone dan kesiapan menjadi faktor kendala utama tidak menggunakan aplikasi wifi TB. Hal ini senada dengan hasil riset yang menunjukkan bahwa persepsi kemudahan dan kemanfaatan dan 
akan mempengaruhi kesediaan untuk menggunakan aplikasi [9-10]. Dari hasil penelitian sebelumnya diketahui bahwa sebuah persepsi yang positif terhadap suatu hal akan mendorong sebuah perilaku sadar untuk mempengaruhi minat dalam menggunakan aplikasi, begitu pula sebaliknya ketika persepsi seseorang mengarah pada persepsi negatif maka akan menurunkan kesadaran seseorang untuk tidak atau enggan menggunakan aplikasi ${ }^{[11]}$.

Jenis smartphone turut menjadi kendala utama responden tidak menggunakan aplikasi. Hasil penelitian menyatakan bahwa warga Italia yang menggunakan smarthphone, 62\%nya memiliki spesifikasi smartphone yang tinggi, dan hampir 50\% menggunakan aplikasi untuk game dan social network sehingga jenis smartphone dapat berdampak pada penggunaan aplikasi [12] Kesiapan responden dapat menggunakan aplikasi juga menjadi salah satu faktor kendala utama. Hasil penelitian menunjukkan bahwa hanya $20 \%$ responden yang siap untuk menerapkan teknologi dalam bekerja sehingga penting untuk menilai kesiapan ehealth rumah sakit untuk menghemat waktu dan uang serta dapat mempersiapkan implementasi TIK dengan lebih baik ${ }^{[13]}$.

\section{KESIMPULAN DAN SARAN}

Berdasarkan hasil analisis data statistik dan deskriptif yang diperoleh dari angket yang diisi oleh responden, dengan mengklasifikasikan berbagai faktor kendala yang disebutkan oleh dokter belum menggunakan aplikasi Wifi TB diperoleh bahwa faktor usia dan akses informasi tidak begitu mendominasi sebagai alasan dokter tidak menggunakan aplikasi Wifi TB. Faktor yang paling mendominasi alasan dokter tidak menggunakan aplikasi wifiTB adalah persepsi negatif $86,2 \%$, tipe smartphone $79,5 \%$ dan kesiapan $78,5 \%$. Oleh karena itu disarankan agar pemerintah membangun persepsi baik agar responden bersedia menggunakan aplikasi Wifi TB.

\section{PERSETUJUAN}

Sesuai standar internasional atau standar universitas, persetujuan tertulis pasien telah dikumpulkan dan disimpan oleh penulis.

\section{PERSETUJUAN ETIS}

Sesuai standar internasional atau standar universitas, persetujuan etika tertulis telah dikumpulkan dan disimpan oleh penulis.

\section{UCAPAN TERIMA KASIH}

Penulis sangat berterima kasih kepada pimpinan dan staf Dinas Kesehatan Kota Semarang dan Fakultas Kesehatan Universitas Dian Nuswantoro sehingga penelitian ini dapat terlaksana dengan baik.

\section{KONFLIK KEPENTINGAN}

Semua penulis menyatakan bahwa kegiatan ini adalah penelitian tanpa konflik kepentingan.

\section{DAFTAR PUSTAKA}

1. WHO. Global Tuberculosis Report 2019 (WHO / CDS / TB / 2018.20). Jenewa. 2019

( https://www.who.int/tb/publications/global _report/tb19_Exec_Sum_12Nov2019.pdf? $\mathrm{ua}=1$ ). Accessed 12 September 2020 .

2. Indah, M. InfoDATIN Data Center and Information Ministry of Health RI. Ministry 
of Health, Data and Information Center. 2018.

https://pusdatin.kemkes.go.id/resources/d ownload/pusdatin/infodatin/infodatin-tuber kulosis-2018.pdf

3. A. Surya, C. Basri, \& S. Kamso. National Guidelines for Tuberculosis Control Directorate General of Disease Control and Environmental Health Of the Ministry of Health of the Republic of Indonesia. $2011 ; 2(2)$.

4. Togun, T., Kampmann, B., Stoker, N. G., \& Lipman, M . Anticipating the impact of the COVID-19 pandemic on TB patients and TB control programmes. Annals of clinical microbiology and antimicrobials. 2020; 19(1):21.

https://doi.org/10.1186/s12941-02000363-1

5. Ministry of Health. Indonesian Health profile 2017 [Internet]. 2017. Available from: www.depkes.go.id/resources /pusdatin/profil-kesehatanindonesia/Profil-Kesehatan-Indonesiatahun-2017.pdf

6. Kurniadi A, Widianawati E, Kusuma EJ, Salim MF. Implementation of TB Wifi Application Based on Perceptions of Ease and Usefulness in Semarang City. 2020;5(2). Available from: https://jurnal.ugm.ac.id/jkesvo/article/view/ 50483

7. Antara M, Prameswari YA. Push and Pull Factors of Tourists Visit the Tourism Destination of Bali, Indonesia. J Tour Hosp Manag. 2018;6(1):2372-5133.
8. Sarlito W Sarwono. Introduction to General Psychology. Jakarta: Rajawali Pers. 2010

9. Teo T, Noyes J. An assessment of the influence of perceived enjoyment and attitude on the intention to use technology among pre-service teachers: A structural equation modeling approach. Comput Educ [Internet]. 2011;57(2):1645-53. Available from: http://dx.doi.org/10.1016/j.compedu.2011. 03.002

10. Marhefka SL, Turner D, Lockhart E. Understanding Women's Willingness to Use e-Health for HIV-Related Services: A Novel Application of the Technology Readiness and Acceptance Model to a Highly Stigmatized Medical Condition. Telemed e-Health. 2019;25(6):511-8.

11. Sudarsono,A., Suharsono Y. Perception of health relationship with mindfulness depositing garbage members of Waste Insurance Clinic in Indonesia Medika. Journal of Applied Psychology Ilimiah, $2016 \quad ; 4$ (1):31-52. DOI: https://doi.org/10.22219/jipt.v4i1.287 6

12. Cardamone AS, Eboli L, Forciniti C, Mazzulla G. Willingness to use mobile application for smartphone for improving road safety. Int J Inj Contr Saf Promot. 2016;23(2):155-69.

13. Gholamhosseini L, Ayatollahi H. The design and application of an e-health readiness assessment tool. Heal Inf Manag

J. $\quad 2017 ; 46(1): 32-41$. 